\title{
Sensitive dependence of trajectories on tracer seeding positions - coherent structures in German Bight backward drift simulations
}

\author{
Ulrich Callies \\ Institute of Carbon Cycles, Helmholtz-Zentrum Hereon, Max-Planck-Str. 1, 21502 Geesthacht, Germany \\ Correspondence: Ulrich Callies (ulrich.callies@hereon.de)
}

Received: 20 August 2020 - Discussion started: 31 August 2020

Revised: 26 January 2021 - Accepted: 18 February 2021 - Published: 9 April 2021

\begin{abstract}
Backward drift simulations can aid the interpretation of in situ monitoring data. In some cases, however, trajectories are very sensitive to even small changes in the tracer release position. A corresponding spread of backward simulations implies attraction in the forward passage of time and, hence, uncertainty about the probed water body's origin. This study examines surface drift simulations in the German Bight (North Sea). Lines across which drift behaviour changes non-smoothly are obtained as ridges in the fields of the finite-time Lyapunov exponent (FTLE), a parameter used in dynamical systems theory to identify Lagrangian coherent structures (LCSs). Results closely resemble those obtained considering two-particle relative dispersion. It is argued that simulated FTLE fields might be used in support of the interpretation of monitoring data, indicating when simulations of backward trajectories are unreliable because of their high sensitivity to tracer seeding positions.
\end{abstract}

\section{Introduction}

A comprehensive monitoring network is operated in the German Bight area (North Sea), including the Marine Environmental Monitoring Network in the North Sea (MARNET), the Coastal Observing System for the North and Arctic Seas (COSYNA) and other stations. Details on the type of data being collected can be found in Baschek et al. (2017). For the same region, Stanev et al. (2016) discuss issues related to modelling and data assimilation with the statistical approach of spatio-temporal optimal interpolation. Advanced statistical methods can also be used for optimizing the design of observational arrays (e.g. Chen et al., 2016; Kim and Hwang, 2020). When it comes to the interpretation of specific data, however, a merely statistical description of spatial connectivity falls short of what can be achieved if hydrodynamic current fields from either models or remote sensing are available.

Backward tracer trajectories seeded at monitoring stations provide insight into the background of water bodies that were probed (e.g. Supplement Video S1; d'Ovidio et al., 2015; Lucas et al., 2016; Teeling et al., 2012). They help distinguish between temporal and spatial variability, i.e. local changes and advection from somewhere else. Backtracking water bodies from hypothetical monitoring stations in the vicinity of Heligoland, Callies et al. (2011) provide an example of how quasi-chaotic mixing in 2D barotropic simulations transforms initially regular into quite contorted structures (see their Fig. 3). Moreover, in nature, forward trajectories of drifters released pairwise may separate quite quickly (e.g. Callies et al., 2019; Meyerjürgens et al., 2020). Therefore, a key question is how reliable backward drift analyses can be and how the numerical analysis of a water body's recent history should be designed. In addition to well-known random dispersion, flow patterns also exist that affect the separation of simulated backward trajectories more systematically (Haller, 2015). The present study focuses on this latter aspect of coherent structures shaping the separation of simulated backward trajectories.

A statistical measure of particle spreading is relative dispersion, the mean square particle distance, as function of time. LaCasce (2008) reviews how this parameter relates to the energy spectrum of a turbulent flow. Relative dispersion is called local when particle separation is dominated by small eddies with a typical scale that compares with particle separation. By contrast, it is termed non-local if particle separation is dominated by eddies much larger than particle sep- 
aration. In the latter case, characterized by a steep energy spectrum, particle separation is expected to grow exponentially. Such high sensitivity to initial particle positions implies what in dynamical systems theory is called chaotic advection (Wiggins, 2005).

Dynamical systems theory aims at a description of the kinematics of turbulent mixing. The approach is based on flow maps that describe particle advection over some time interval, according to Haller (2015) "thereby mimicking experimental flow visualization by tracers". This technique has been widely applied for analysing the microstructure of chaotic mixing processes in 2D (e.g. Pierrehumbert and Yang, 1993), describing how chaotic advection may transform initially small discs of fluid into complex filamentary structures. Trying to improve the sometimes vague definitions of such structures, Haller and Yuan (2000) introduced the framework of Lagrangian coherent structures (LCSs). Their method seeks to identify material lines that function as only weakly permeable barriers for water body transport, attracting or repelling neighbouring trajectories. Peacock and Haller (2013) provide a nice overview of the topic.

Attracting LCSs, in dynamical systems theory also called unstable because of a fast stretching of particles along them (according to Harrison and Glatzmaier, 2010, an unfortunate historical definition), have been used for optimizing drifter deployments in field studies. Poje et al. (2002) proposed drifter deployment into attracting LCSs to ensure fast dispersal based on near-exponential material stretching, which lets drifters explore regions of high kinetic energy. Molcard et al. (2006) used this approach for assimilating drifter velocities into an ocean general circulation model. Different from these studies, Shadden et al. (2009) focus on repelling LCSs. Seeding drifters in a less localized way, Shadden et al. (2009) tried to make drifters stay in a specific region delineated by transport barriers for as long as possible. They exemplified that a LCS's robustness might enable extrapolation of its separatrix function even beyond the time horizon of detailed operational hydrodynamic predictions (e.g. 3 d). Combining SeaWiFS Ocean Colour data with altimetry-derived surface currents in the Brazil-Malvinas confluence zone, d'Ovidio et al. (2010) found that stirring by mesoscale currents can play an important role in structuring phytoplankton communities and even create what they called fluid dynamical niches, sharply delimited by LCSs. Hernández-Carrasco et al. (2018) study this topic at the sub-mesoscale, using currents observed with high-frequency (HF) radar in coastal waters. According to Scales et al. (2018), attracting LCSs can also be targeted by fisheries, led by lines of drifting foam or debris.

Conducting backward simulations, the present study proposes the use of LCSs as indicators of a possibly sensitive dependence of measurements on where and when exactly they were taken. The analysis is based on offline drift simulations using German Bight surface layer currents obtained from archived output of the operational 3D baroclinic model BSHcmod, run operationally by the German Federal Mar- itime and Hydrographic Agency (BSH). The study aims for an assessment of the situations at specific times of interest rather than for a generic characterization or classification of given locations. Highly variable transport paths in the German Bight area for the most part arise from residual currents driven by changing wind conditions (Schrum, 1997; Callies et al., 2017a). Establishing a simple interrelationship between winds and overall finite-time transports is hardly possible, as tracer trajectories may aggregate the effects of very different winds. Detailed numerical simulations, however, properly integrate such variable hydrodynamic transports during a specific observation period.

Hadjighasem et al. (2017) compare 12 candidate approaches that could be used for the identification of LCSs. Among those, calculation of finite-time Lyapunov exponents (FTLEs) is one of the most common methods. The FTLE is closely related to the finite-size Lyapunov exponent (FSLE), originally introduced by Aurell et al. $(1996,1997)$ and used in experiments for diagnosing scale-dependent separation rates between drifter pairs (LaCasce and Ohlmann, 2003; Sansón et al., 2017). Karrasch and Haller (2013), however, report some limitations for FSLEs in LCS detection, suggesting that an approach based on FTLE distributions may be more reliable. The FTLE fields are independent of an observer's reference frame (Haller, 2015), representing the rate at which neighbouring tracers separate according to the largest eigenvalue of the Cauchy-Green strain tensor.

Building on work by Haller (2001), Shadden et al. (2005) define LCSs in terms of ridges in the FTLE field. In 2D, the LCSs are material lines transported with the flow that, in good approximation, act as transport barriers. Discussing some counterexamples in which substantial material flowed across a FTLE ridge, Haller (2011) developed a more sophisticated variational approach. Farazmand and Haller (2012) presented a corresponding numerical algorithm for 2D applications. Recently Tian et al. (2019) applied a variational method to identify the outer bounds of the Kuroshio Current system. Here, the analysis will adhere to conventional FTLE fields.

This paper is organized as follows: Sect. 2 first describes the study area and how Lagrangian drift simulations were performed based on precalculated hydrodynamic surface current fields. This is followed by a short compilation of the definitions of the FTLE, stretch, Lagrangian divergence and statistical measures of dispersion. Presenting a couple of structures that emerged under different wind conditions, Sect. 3 then provides an overview of the types of LCSs that can be found in the German Bight area. Example trajectories substantiate the relevance of FTLE ridges as material separatrices. A general discussion and a short summary conclude the paper. 


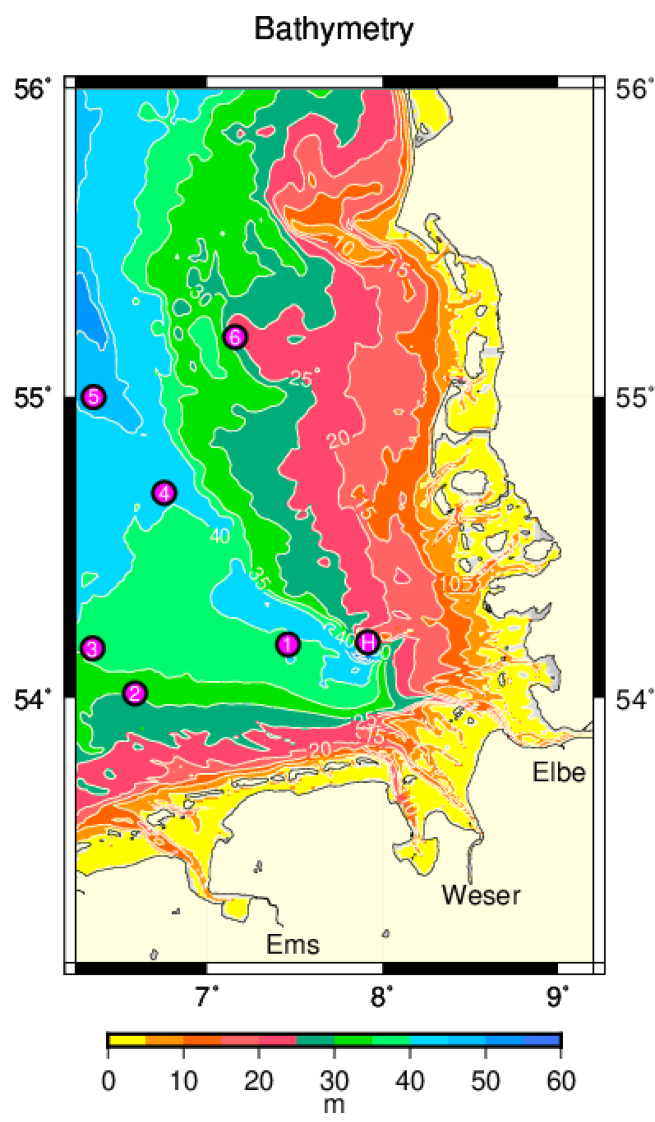

Figure 1. German Bight bathymetry. The magenta circles indicate the locations of six stations of the MARNET monitoring network (1-6) and of the island of Heligoland (H).

\section{Material and methods}

\subsection{Study area}

The North Sea is a semi-enclosed shelf sea that connects to the north-eastern Atlantic at its northern boundary and through the English Channel at its south-west (Sündermann and Pohlmann, 2011). Strong tidal forcing occurs as a cooscillation triggered by Atlantic tidal waves. This study focuses on the German Bight, the shallow south-eastern part of the North Sea (here, south of $56^{\circ} \mathrm{N}$ and east of $6.5^{\circ} \mathrm{E}$ ) with general water depths of between 20 and $50 \mathrm{~m}$ (see Fig. 1), adjoining the Dutch, German and Danish coasts (Becker et al., 1992). In the German Bight, a mean cyclonic North Sea circulation corresponds to residual currents from the southwest to the north. Superimposed onto this mean circulation, a strong weather-driven variability occurs on short timescales (Schrum, 1997; Callies et al., 2017a). A fresh water plume emerging from the Elbe River and, to a minor extent, also the Weser and the Ems rivers can be observed as a permanent feature. Transient eddies and meanders depend on bottom topography, baroclinic instabilities and wind effects.
The most important topographic feature is the old Elbe glacial valley, opening from today's Elbe estuary towards the north-west into the open North Sea (see Fig. 1). Becker et al. (1992) summarize different types of fronts (river plume, thermal and upwelling fronts) that occur in the German Bight. Frontal structures depend on season but also vary on a shortterm basis (Budéus, 1989; Schrum, 1997). In the warm season, strong stratification occurs at water depths greater than approximately $30 \mathrm{~m}$, mainly in the Elbe glacial valley. A baroclinic tidal mixing front (James, 1984; Holt and Umlauf, 2008) separates this region from the well-mixed shallower coastal water, where stratification is prevented by strong tidal mixing (Krause et al., 1986).

\subsection{Hydrodynamic fields}

Surface layer currents used for offline drift simulations (see Sect. 2.3) as well as temperature fields were taken from archived BSHcmod model output. BSHcmod is a 3D baroclinic circulation model, formulated using geographical coordinates and a flexible vertical resolution that allows for weakly inclined coordinate surfaces (Dick et al., 2008) of up to 36 layers. The model has been run operationally by the German Federal Maritime and Hydrographic Agency (BSH) for many years, providing the basis for different oceanographic services including search and rescue applications. It covers both the North Sea and the Baltic Sea and is two-way nested with approximately $900 \mathrm{~m}$ resolution in the German Bight area (Fig. 1) and $5 \mathrm{~km}$ in the open North Sea (Dick et al., 2001). The domain of the present analysis roughly agrees with the region of fine resolution in German North Sea coastal waters.

In BSHcmod, advection and diffusion are calculated using a flux-corrected transport scheme. The hydrostatic and the Boussinesq approximations are applied. The Smagorinsky scheme (Smagorinsky, 1963) is used for the parameterization of horizontal viscosity. For an inclusion of wind stress, the parametrization by Smith and Banke (1975) is used. Stokes drift remains disregarded in the operational model output. The model's atmospheric forcing is provided by the regional model COSMO-EU (Consortium for Small-Scale Modelling; Schulz and Schättler, 2014), run by the German Meteorological Service (Deutscher Wetterdienst, DWD). The Swedish Meteorological and Hydrological Institute (SMHI) and the Federal Institute of Hydrology (BfG) provide runoff data for all major rivers that flow into the North Sea.

In the archiving process, BSHcmod hydrodynamic fields with originally higher vertical resolution were re-gridded. Conserving transport rates, this was done in such a way that the archived surface currents used in this study are representative of the uppermost $5 \mathrm{~m}$ of the water column. With drift simulations based on these currents plus a leeway of $0.6 \%$ of winds at $10 \mathrm{~m}$ height, Callies et al. $(2017 \mathrm{~b}, 2019)$ reproduced observed drifter trajectories reasonably well. 


\subsection{Lagrangian drift simulations}

Offline drift simulations based on BSHcmod surface layer currents (archived on a 15 min basis) were performed using the Lagrangian transport program PELETS-2D (Callies et al., 2011). Originally, the PELETS toolbox, developed at Helmholtz-Zentrum Hereon (formerly the HelmholtzZentrum Geesthacht), was designed for use with hydrodynamic currents on unstructured triangular grids. Current fields provided on a regular grid (like those from BSHcmod) must be preprocessed, splitting each rectangular grid cell into two triangles, which is a transformation of grid topology that does not affect the information content of hydrodynamic fields.

All simulations in this study were produced using the fourth-order Cash-Karp method (Press et al., 1992) that belongs to the Runge-Kutta family of solvers. A simple Euler forward scheme, however, used in other PELETS applications (e.g. Callies et al., 2011, 2017b, 2019) gave very similar results. The maximum time step is set to $15 \mathrm{~min}$. Velocities are updated earlier every time that a tracer particle moves to another triangular grid cell.

\subsection{Finite-time Lyapunov exponents (FTLE)}

Definition of the FTLE is based on a consideration of Lagrangian flow motions. A flow map $\Phi$ maps particle locations $\boldsymbol{x}_{0}$, where particles were seeded at time $t_{0}$, onto their destinations $\boldsymbol{x}$ at later time $t=t_{0}+\tau$ :

$\Phi_{t_{0}}^{\tau}\left(\boldsymbol{x}_{0}\right)=\boldsymbol{x}\left(t_{0}+\tau ; t_{0}, \boldsymbol{x}_{0}\right)$.

The following deformation gradient describes material deformation:

$\nabla \Phi_{t_{0}}^{\tau}\left(\boldsymbol{x}_{0}\right)=\left(\begin{array}{ll}\frac{\partial x}{\partial x_{0}} & \frac{\partial x}{\partial y_{0}} \\ \frac{\partial y}{\partial x_{0}} & \frac{\partial y}{\partial y_{0}}\end{array}\right)$,

where $\boldsymbol{x}=(x, y)$. The deformation's Jacobian provides the ratio of the area $A$ of a deformed quadrangle to the area $A_{0}$ of an infinitesimal square that it has its origin in. In case of a finite size initial square and a non-linear flow, this ratio refers to a quadrangle that approximates the emerging distorted patch. Similarly, a linear map sends an initially small circle to an ellipse. The lengths of the image area's semi-axes are given by the deformation gradient's two singular values, $\mu_{1}$ and $\mu_{2}$, whose product equals the Jacobian determinant:

$\frac{A}{A_{0}}=\operatorname{det}\left(\nabla \Phi_{t_{0}}^{\tau}\right)=\mu_{1} \mu_{2}$.

From the above deformation gradient, one obtains the following Cauchy-Green strain or deformation tensor (e.g. Shadden et al., 2005; Haller, 2015):

$C\left(\tau ; t_{0}, \boldsymbol{x}_{0}\right)=\left[\nabla \Phi_{t_{0}}^{\tau}\left(\boldsymbol{x}_{0}\right)\right]^{T} \nabla \Phi_{t_{0}}^{\tau}\left(\boldsymbol{x}_{0}\right)$.
This $2 \mathrm{D}$, symmetric and positive-definite tensor has two eigenvalues, $\lambda_{1}=\mu_{1}^{2}$ and $\lambda_{2}=\mu_{2}^{2}$. The definition of the finite-time Lyapunov exponent (FTLE) is based on the tensor's larger eigenvalue $\lambda_{1}$ :

$\operatorname{FTLE}\left(\tau ; t_{0}, \boldsymbol{x}_{0}\right)=\frac{1}{|\tau|} \log \sqrt{\lambda_{1}}=\frac{1}{|\tau|} \log \left(\mu_{1}\right)$.

The absolute value of integration time $\tau$ is used because integration of particle drift can be conducted either forward or backward in time. The geometric interpretation of the FTLE refers to the maximum separation rate of neighbouring particles (Haller, 2015).

To compute FTLE fields numerically, a regular Cartesian grid of tracers was released: initial locations with $1 \mathrm{~km}$ resolution covering the German Bight area south of $56^{\circ} \mathrm{N}$ and east of $6.5^{\circ} \mathrm{E}$ ( 310 vortices in the latitudinal direction and 165 vortices in the longitudinal). The corresponding 51150 trajectories were integrated $250 \mathrm{~h}$ back in time $(\tau=-250 \mathrm{~h})$. To avoid the computational burden of four close-by auxiliary trajectories, finite-differencing in Eq. (2) was performed based on neighbouring trajectories seeded on the regular FTLE grid.

In view of the limited vertical resolution of archived BSHcmod currents, values of the deformation gradient (Eq. 2) were tagged as missing each time at least one of the four tracer trajectories needed for its discrete calculation encountered a water depth of less than $5 \mathrm{~m}$ sometime in the course of its integration. Resulting gaps in the fields of FTLE and related quantities change with variable atmospheric forcing. As BSHcmod covers the whole North Sea, no specific treatment is needed for particles that cross the open boundaries of the FTLE grid.

\subsection{Distinction between divergence and stretch}

An incompressible 2D flow field preserves the area of a Lagrangian patch during arbitrary deformations. Here, however, 2D surface currents being used were extracted from 3D hydrodynamic fields that allow for vertical exchange of water masses. Huntley et al. (2015) developed a concept that splits FTLE values into contributions that come from area-preserving stretching and deformation on the one hand and area changes on the other hand. Given the singular values $\mu_{1} \geq \mu_{2}$ of the deformation gradient $\nabla \Phi_{t_{0}}^{\tau}\left(\boldsymbol{x}_{0}\right)$, Huntley et al. (2015) introduced the following stretch rate $\Sigma$ :

$\Sigma=\frac{1}{|\tau|} \log \left(\frac{\mu_{1}}{\mu_{2}}\right)$.

In addition, they introduced the following dilation rate $\Delta$ that describes the transformation of a infinitesimal Lagrangian patch's initial area $A_{0}$ to an area $A$ after integration time $\tau$ :

$\Delta=\frac{1}{|\tau|} \log \left(\frac{A}{A_{0}}\right)=\frac{1}{|\tau|} \log \left(\mu_{1} \mu_{2}\right)$, 
where Eq. (3) has been used. From Eq. (5) it follows that the separation rate represented by the FTLE can be decomposed in terms of the above two components:

FTLE $=\frac{\Delta+\Sigma}{2}$.

Dilation rate $\Delta$ can be shown to equal the average Eulerian horizontal divergences experienced by a fluid parcel along its pathway (Huntley et al., 2015; Duran et al., 2018, supporting information). From the material derivative

$\frac{d A}{d t}=A \nabla_{H} \cdot \boldsymbol{v}$,

it follows that

$A(\tau)=A_{0} \exp \left(\int_{t_{0}}^{t_{0}+\tau} \nabla_{H} \cdot \boldsymbol{v}\left(t^{\prime}, \boldsymbol{x}\left(t^{\prime} ; t_{0}, \boldsymbol{x}_{0}\right)\right) \mathrm{d} t^{\prime}\right)$.

Hernández-Carrasco et al. (2018) referred to the patch area's change rate, derived from past Eulerian divergences, as the finite-domain Lagrangian divergence (FDLD):

$$
\begin{aligned}
\operatorname{FDLD}\left(\tau ; t_{0}, \boldsymbol{x}_{0}\right) & =\frac{1}{|\tau|} \log \left(\frac{A}{A_{0}}\right) \\
& =\frac{1}{|\tau|} \int_{t_{0}}^{t_{0}+\tau} \nabla_{H} \cdot \boldsymbol{v}\left(t^{\prime}, \boldsymbol{x}\left(t^{\prime} ; t_{0}, \boldsymbol{x}_{0}\right)\right) \mathrm{d} t^{\prime} .
\end{aligned}
$$

They demonstrated its potential for supporting the interpretation of satellite-based observations of surface chlorophyll $a$ patches.

Analytically, the FDLD from Eq. (11) equals dilation rate $\Delta$ from Eq. (7). In the present study, however, the Eulerian divergences needed for the numerical evaluation of Eq. (11) were computed based on auxiliary points introduced at a $250 \mathrm{~m}$ distance. Corresponding velocities were obtained by linear interpolation. As a result of this refinement, truncation errors due to numerical discretization differ from those of analyses on the basic $1 \mathrm{~km}$ FTLE grid.

\subsection{Absolute and relative dispersion}

Absolute and relative dispersion are statistical measures for analysing Lagrangian data. Generally, absolute dispersion is defined as the second moment of the probability density function (PDF) of single particle displacements, i.e. the variance of particle displacements relative to their starting position. This measure must not be confused with cloud variance (LaCasce, 2008). Ensemble averaging could be performed with respect to either different locations or different realizations at some fixed location. Here, following Haller and Yuan (2000), the simpler density of absolute dispersion is considered, describing just one single particle's squared displacement from its release point:

$a^{2}\left(\tau ; t_{0}, \boldsymbol{x}_{0}\right)=\left|\boldsymbol{x}\left(t_{0}+\tau ; t_{0}, \boldsymbol{x}_{0}\right)-\boldsymbol{x}_{0}\right|^{2}$.
By contrast, relative dispersion describes the mean square separation of particle pairs with nearby initial release points. Relative dispersion at each node of the FTLE grid will be calculated by combining the information from four particle pairs:

$$
\begin{aligned}
D^{2}\left(\tau ; t_{0}, \boldsymbol{x}_{0}\right) & =\frac{1}{4} \sum_{i=1}^{4} \mid \boldsymbol{x}\left(t_{0}+\tau ; t_{0}, \boldsymbol{x}_{0}\right) \\
& -\left.\boldsymbol{x}\left(t_{0}+\tau ; t_{0}, \boldsymbol{x}_{0}+\delta \boldsymbol{x}_{i}\right)\right|^{2},
\end{aligned}
$$

where $\delta \boldsymbol{x}_{i}$ denotes the distance vector between neighbouring nodes. For a comparison with FTLE and FDLD fields, the logarithm of absolute and relative dispersion is a reasonable choice. Exponential growth of pair separations indicates the presence of Lagrangian chaos, which dynamical systems theory deals with (Wiggins, 2005).

\section{Results}

A couple of examples will be given that are intended to illustrate the occurrence and time variability of Lagrangian structures in German Bight surface currents. All of the analyses shown will be based on a backward integration time of $-250 \mathrm{~h}$. However, this specific choice has no crucial impact on the structures being shown. None of the sometimes sharp structures observed are persistent, and the occurrence and specific patterns depend on the past evolution of atmospheric forcing. For this reason, all figures contain wind roses that summarize the wind conditions during the previous $250 \mathrm{~h}$.

\subsection{FTLE and Lagrangian divergence}

Figure 2a shows the FTLE field for simulations initialized on 12 June 2015 (13:00 UTC) and extending over $250 \mathrm{~h}$ backward in time. The graph leaves all locations blank from where trajectories reached regions with water depths below $5 \mathrm{~m}$. At the time Fig. 2 refers to, the most prominent feature in the FTLE field is an extended south-north-running ridge of high FTLE values. Further west, a less pronounced parallel second ridge occurs that tends to be split into three or four segments. Other more local and sometimes also weaker filamentary structures can be recognized. With the intention of illustrating the physical relevance of the central FTLE ridge, Fig. 2a includes three groups of four $250 \mathrm{~h}$ backward trajectories, initialized in the wider neighbourhood of stations 1 , 4 and 6 of the MARNET monitoring network ${ }^{1}$. To facilitate orientation and comparison, the locations of the six MARNET stations and the island of Heligoland (station $\mathrm{H}$ ) will be indicated in all further figures.

The experiment shown refers to a situation with calm conditions during the last $3 \mathrm{~d}$, with weak winds blowing from the

\footnotetext{
${ }^{1}$ Station names: Deutsche Bucht (1), FINO1 (2), Ems (3), Nordseeboje III (4), Nordseeboje II (5) and FINO3 (6)
} 
north/north-east under the influence of a high-pressure system centred further west. Vectors in the top right corner of Fig. 2a show simulated $10 \mathrm{~m}$ wind directions near MARNET station 4 during the past $250 \mathrm{~h}$ at 10 -hourly intervals. Wind speeds are represented using a colour code. The wind vector at the time of the plot is outlined in red and those during the last $50 \mathrm{~h}$ are outlined in black. Strong winds $(>17 \mathrm{~m} / \mathrm{s})$ from the south/south-west occurred on the 2 and 3 June, i.e. at the end of the $250 \mathrm{~h}$ backward integration period. Another period with enhanced wind speeds $(<10 \mathrm{~m} / \mathrm{s})$ occurred about 4-6 d before the time of the FTLE field that is shown. At that time, winds from the south-west/west changed to winds from roughly northern directions.

Both the directional changes and the higher drift speeds at the end of the integration back in time can also be recognized from the example drift trajectories displayed in Fig. 2a. Two pairs of hypothetical in situ observation points (indicated by small green and blue circles) were located on either side of the central FTLE ridge near MARNET stations 1 and 6. Trajectory end points are indicated by small diamonds. Simulations show a clear separation of those backward trajectories that emerge from different sides of the FTLE ridge. By contrast, trajectories started on the same side of the ridge (shown using the same colour) remain close to each other. The examples illustrate how even nearby or adjacent in situ observations may encounter water bodies with a much different history. Figure 2a also shows a complementary experiment, in which release points near MARNET station 4 are now all located within an area of low FTLE values. In this case, all trajectories stay close together or even further converge.

Separation in backward time means confluence in ordinary forward time. Therefore, the negative backward Lagrangian divergence FDLD (see Eq. 11) shown in Fig. 2b is to be read in agreement with the usual passage of time. Figure $2 b$ reveals a striking structural similarity with Fig. $2 a$. Water parcels located on backward FTLE ridges have predominantly experienced converging surface currents along their pathway during the last $250 \mathrm{~h}$. Between the ridges, there are wider regions with particles with a history dominated by divergent Eulerian currents.

Studying the Agulhas Current in the south-west Indian Ocean, van Sebille et al. (2018, their Fig. 3) found structures in fields of sea surface temperature (SST) that agreed with LCSs derived from geostrophic currents. For the present example, Fig. 2c shows a south-north-oriented zone of relatively cool surface layer water, located in between narrow bands of higher temperature that tend to coincide with the FTLE ridges (Fig. 2a) and zones of convergence (Fig. 2b). The belt is made up by a couple of patches that bear a structural resemblance to patches of positive divergence in Fig. 2b, suggesting that some features of the temperature distribution in Fig. 2c can indeed be explained in terms of upwelling and downwelling simulated in the model. Meyerjürgens et al. (2020) found reduced relative dispersion for ex- perimental drifters released in the vicinity of a tidal mixing front, indicating horizontal attraction in this region.

\subsection{Influences of bathymetry and wind conditions}

Figure $3 \mathrm{~b}$ shows a backward FTLE field that is even more clearly structured than the one in Fig. 2a, also including pronounced west-east-oriented divides. Note that FTLE ridges in the western part of the domain closely follow the bathymetric feature of the old Elbe glacial valley (see Fig. 1). Again, the origins of example tracers, estimated by backward trajectories with nearby release points (green and blue) on either side of FTLE ridges, vastly differ. Particularly large differences occur for the most northern and the most southern trajectories.

Similarly to the example shown in Fig. 2, calm atmospheric conditions also prevailed for a couple of days preceding the time of Fig. 3b (26 March 2018, 18:00 UTC). Very strong easterly winds, however, persisted for a couple of days towards the end of the $250 \mathrm{~h}$ backward integration period (roughly 16-18 March). Nearly constant easterly wind directions for the last $50 \mathrm{~h}$ can be distinguished from the wind rose in Fig. 3a, showing the FTLE field $8 \mathrm{~d}$ earlier. Trajectories of North Sea drifters observed under these rare conditions (due to low temperatures in the UK called the "Beast from the East") have been discussed by Stanev et al. (2019, see Fig. 3a therein). Some FTLE ridges that emerge according to Fig. 3a are aligned parallel with the easterly winds and seem to correspond with or to transform into sharp FTLE ridges in Fig. $3 \mathrm{~b}$ under the subsequent much calmer conditions.

For comparison purposes, Fig. 3c shows an example of a much less structured FTLE field on 11 June 2016 (03:00 UTC) after persistently moderate winds from northerly directions. In this case, sharp FTLE ridges are nearly absent. Overlaid on the FTLE field, Fig. 3c includes direct counterparts of the trajectories shown in Fig. 3b, released at exactly the same locations. Contrary to the situation in Fig. 3b, now all neighbouring trajectories are very much alike, mainly shifted in agreement with the slightly modified release points. Similar behaviour also occurs at the time of Fig. 3b when particles are released away from the FTLE ridges (see Fig. S1 in the Supplement).

\subsection{FTLE and measures of dispersion}

29 February 2016 (Fig. 4a) provides another example of weak winds that follow more stormy conditions. On about 26 February, strong winds to the south of an atmospheric low make way for weaker winds under the influence of a highpressure system. Different from the previous example, however, the strong winds some days prior persistently blew from the west rather than from the east (see also the video provided in the Supplement). Again, a net of sharp FTLE ridges can be observed in Fig. 4a. 

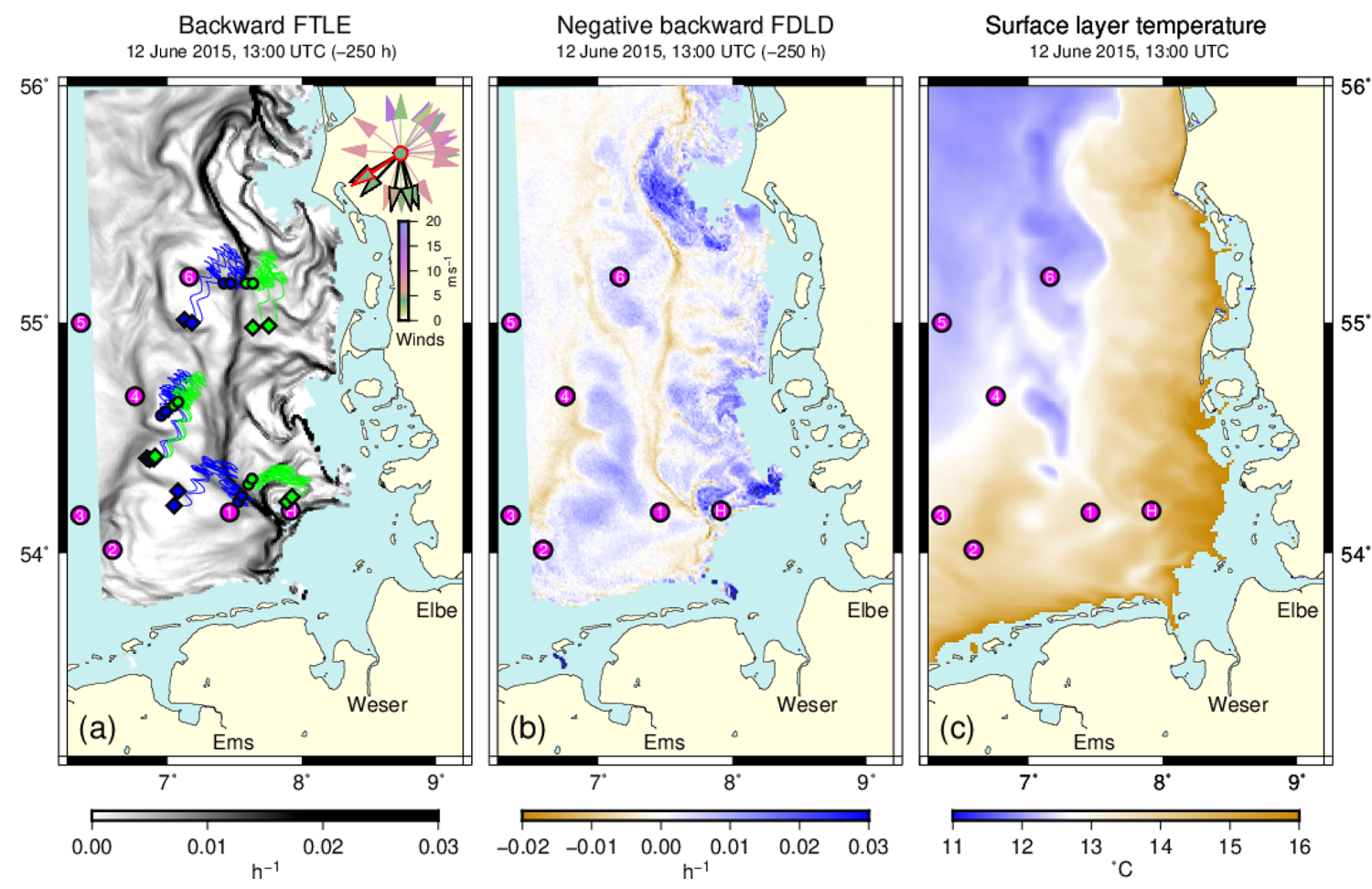

Figure 2. (a) The FTLE field analysed for 12 June 2015 (13:00 UTC), evaluating Eq. (5) based on trajectories calculated $250 \mathrm{~h}$ backward in time. The scale was chosen to adequately visualize ridges of large values. Negative values of the logarithmic FTLE have been plotted as if they were zero. Locations from where trajectories encountered a water depth of less than $5 \mathrm{~m}$ sometime in the course of their integration were disregarded. Example backward trajectories are shown using different colours (green and blue) for better distinction. Trajectory release points are indicated by circles, and end points are indicated by diamonds. Labelled circles (magenta) indicate the locations of six stations of the MARNET monitoring network (1-6) and of the island of Heligoland (H). Vectors in the top-right corner show past wind directions at 10-hourly intervals, referring to simulations for the location of MARNET station 4. Different wind speeds are represented by different colours. The wind vector at the time of the plot is outlined in red and those during the last $50 \mathrm{~h}$ are outlined in black. (b) Negative Lagrangian divergences (FDLD) calculated from Eq. (11). The few large positive values, exceeding the range covered by the colour map, are plotted in dark blue. (c) Simulated mean temperatures in the uppermost $5 \mathrm{~m}$. To focus on open-sea conditions, temperatures higher than $16^{\circ} \mathrm{C}$ are not shown.

Figure $4 \mathrm{~b}$ and $\mathrm{c}$ analyse the situation in terms of statistical dispersion measures. Figure $4 \mathrm{~b}$ displays the spatial distribution of absolute dispersion. Each pixel in the plot represents the squared distance between the corresponding trajectory's release and end point. The plot reveals some sharp demarcations between zones with either broadly similar or at most smoothly changing drift velocities. A measure that directly concentrates on small-scale changes in drift behaviour is two-particle relative dispersion (Fig. 4c). Its distribution closely resembles the FTLE field in Fig. 4a. Furthermore, the two maps of absolute and relative dispersion are in very good agreement, with relative dispersion highlighting sharp transitions in the graph of absolute dispersion.

Figure $4 \mathrm{~b}$ includes some example trajectories. Test trajectories near the horizontal divide south of MARNET station 4 illustrate a stepwise change in advection speed, giving rise to the enhanced level of absolute dispersion for the hypothetical station located more to the south (green). Note that a pure change in drift direction, maintaining advection speed, would have affected relative but not absolute dispersion. Three additional trajectories (magenta), seeded at MARNET stations 1, 2 and 6 , were included to visualize the spatial variability of transports.

\subsection{Temporal development of FTLE fields}

A video in the Supplement, based on one FTLE field every $7 \mathrm{~h}$, shows the variability of FTLE ridges throughout the year 2016. Figure 5a-c are extracted from this video. They illustrate the development within the 2 week period from 22 November to 6 December 2016.

Figure 5a shows the situation after $10 \mathrm{~d}$ of mostly strong winds from between the south-east and west. The FTLE field is much less compartmentalized than the fields in Figs. $3 \mathrm{~b}$ and $4 \mathrm{a}$, for instance. Instead, it shows long FTLE ridges aligned in a meridional direction, resembling the pattern in Fig. 2a. On 23 November, winds blowing from southern directions changed to winds from northern directions, which 


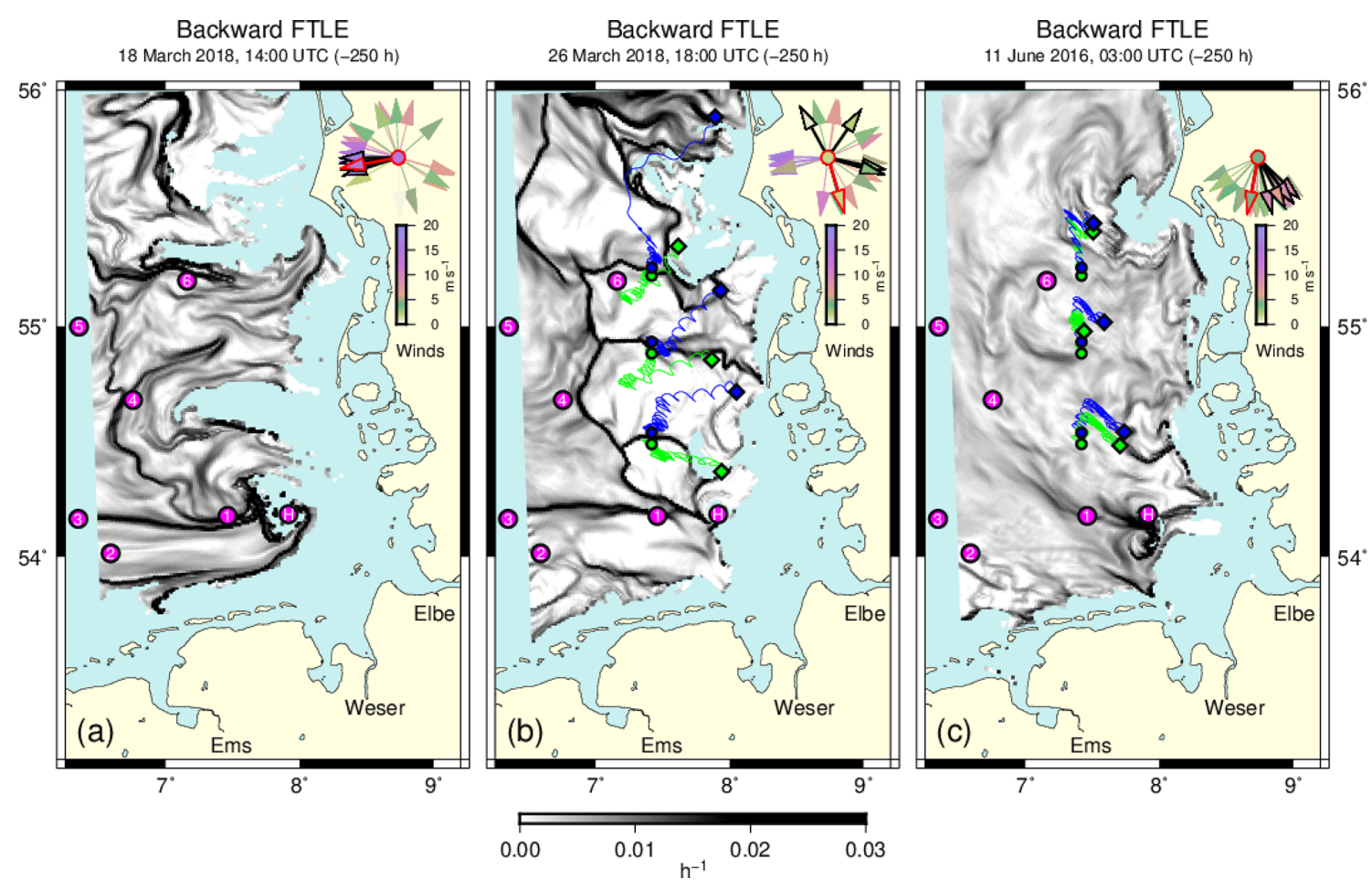

Figure 3. (a) Backward FTLE field (250h integration) for 18 March 2018 (14:00 UTC). Magenta circles indicate the locations of the MARNET stations (1-6) and of the island of Heligoland (H). (b) Backward FTLE field about $8 \mathrm{~d}$ later (26 March 2018, 18:00 UTC). Three pairs of example trajectories (green and blue), started on either side of FTLE ridges, are shown. Trajectory release points are indicated by circles, and end points are indicated by diamonds. (c) Example of a much smoother backward FTLE field on 11 June 2016 (03:00 UTC). For the purposes of comparison, backward trajectories were calculated from the same release points as those used in panel (a). Vectors in the top-right corner of each panel show past wind directions (modelled for the location of MARNET station 4) at 10-hourly intervals. Different wind speeds are represented using different colours. Wind vectors at the times plots refer to are outlined in red and those during the previous $50 \mathrm{~h}$ are outlined in black.

entailed a reversal of the formerly pronounced cyclonic circulation to an anticyclonic marine residual circulation (see https://www.bsh.de/DE/DATEN/Stroemungen/ Zirkulationskalender/zirkulationskalender_node.html,

last access: 29 March 2021). The wind rose in Fig. 5b (27 November, 21:00 UTC) clearly separates a cluster of southern winds underlying Fig. 5a from the more recent northern winds. It can be seen that this transition of winds generates structures which also include more east-westoriented ridges (Fig. 5b). After 3 December, a high-pressure area with very low winds extends into the North Sea region. Under such calm conditions, the FTLE field shown in Fig. 5c suggests a development towards a more cellular structure.

\section{Discussion}

Taking a monitoring perspective, this study focused on the analysis of attracting LCSs in the German Bight, technically identified as repelling LCSs in backward simulations. Drift simulations based on BSHcmod surface layer currents revealed a pronounced time variability of LCSs, driven by changing wind conditions. Some LCSs, identified as ridges in the FTLE field, were found to be surprisingly sharp (see Figs. $3 \mathrm{~b}$ or $4 \mathrm{a}$ ), so that measurements at neighbouring locations might see water bodies with very different backgrounds. Similarly, at a given station, even a small windinduced displacement of the FTLE field could substantially shift the origins of water bodies being probed. Being aware of such sensitivities can be relevant for a proper interpretation of observational data. Ridges in the simulated backward FTLE field convey the information in a clear and amenable way.

The general idea followed here differs from the objective of studies such as Ricker and Stanev (2020), who aimed at the identification of mean particle accumulation patterns (in forward mode) on the European north-west shelf on timescales of months or years. In the light of time-dependent, sometimes narrow FTLE ridges, a general characterization of monitoring stations in terms of their areas of influence seems difficult to achieve. Duran et al. (2018) derived climatological LCSs (cLCS) based on low-pass-filtered velocity fields. These cLCSs could then successfully be applied for a description of quasi-steady transport patterns in the Gulf of 

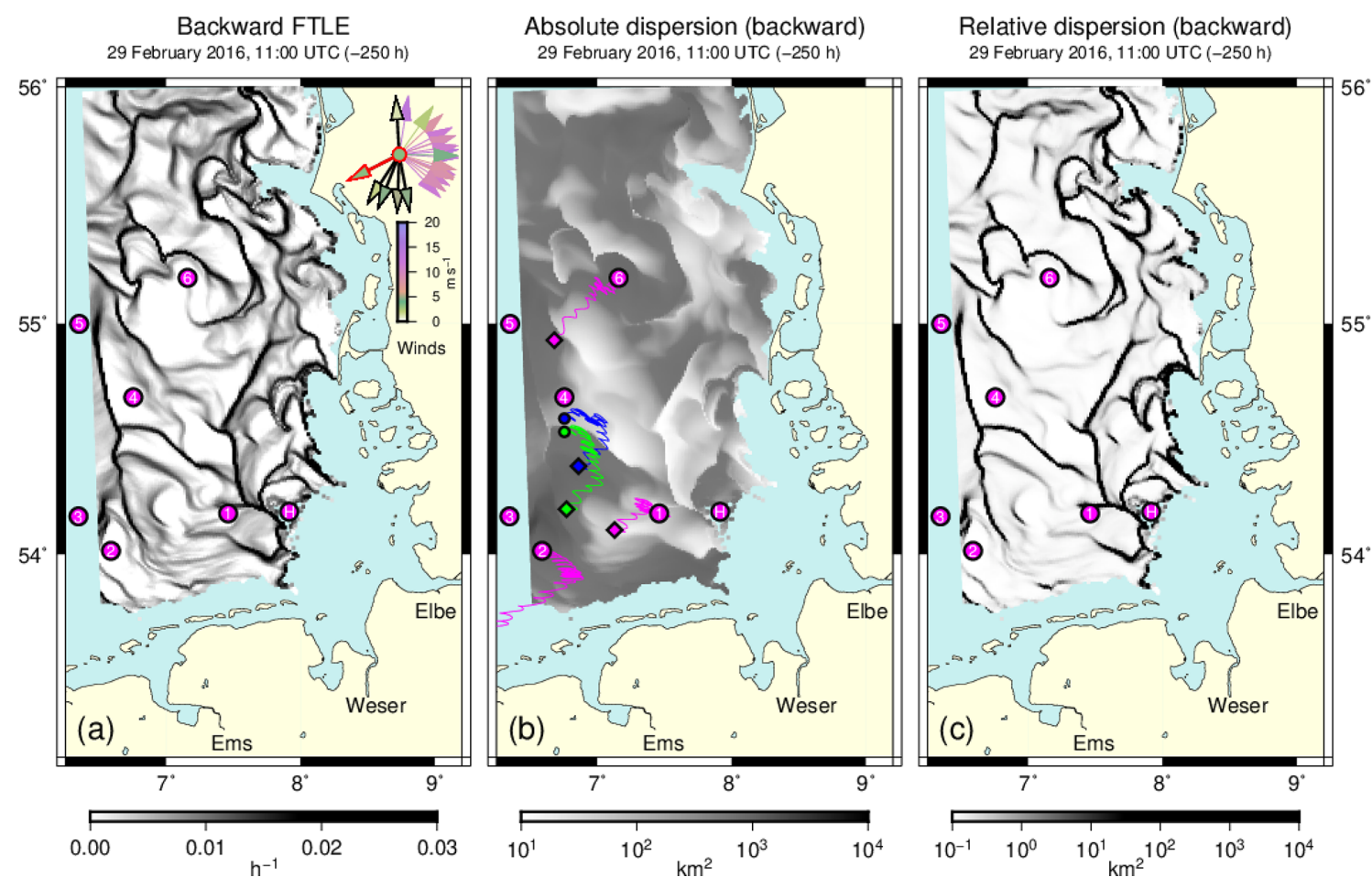

Figure 4. (a) Backward FTLE field (integration time 250h) for 29 February 2016 (11:00 UTC). Magenta circles indicate the locations of the MARNET stations (1-6) and of the island of Heligoland (H). Vectors in the top-right corner show past wind directions (modelled for the location of station 4) at 10-hourly intervals. Different wind speeds are represented by a colour map. The wind vector at the time of the plot is outlined in red and those during the last $50 \mathrm{~h}$ are outlined in black. (b) Absolute dispersion (see Eq. 12) for the same time. Example trajectories shown were initialized at MARNET monitoring stations 1, 2 and 6 (magenta) as well as at two locations (small circles in blue and green) neighbouring MARNET station 4 to its south. Small diamonds indicate each trajectory's final location. (c) The distribution of relative dispersion (see Eq. 13) for the same time.

Mexico. Marine currents in the German Bight area, however, are much more variable. Therefore, this study suggests the use of detailed numerical simulations to classify probed water bodies with respect to their presumable source regions. Similarly, detailed transport modelling could support the effective organization of field experiments. Not looking into the future, backward FTLE fields can already be simulated at the time when observations are actually taken. Such timely model-based information on existing LCSs would allow for an adjustment of field campaigns to prevailing environmental conditions in the light of the data already gathered.

The examples shown suggest that particular strong wind conditions trigger the occurrence of pronounced FTLE ridges. These ridges are often of considerable length and sometimes demarcate a net of closed subregions. They also continue to exist for some time under subsequent calmer wind conditions (e.g. Fig. 3a and b). Throughout this study, all FTLE values were calculated based on trajectories integrated $250 \mathrm{~h}$ back in time. This integration time is much longer than the few tidal cycles that Orre et al. (2006) chose to analyse topographically constrained currents in a Norwegian fjord. Huhn et al. (2012) chose $24 \mathrm{~h}$ for their study in the Ria de Vigo estuary, to prevent tracer particles from reaching the boundaries. In the present study, all trajectories that met water depths below $5 \mathrm{~m}$ were discarded. The long $-250 \mathrm{~h}$ integration time implies that even when backward trajectories are started under calm atmospheric conditions, they can nevertheless also experience a storm event that occurred a couple of days ago. A very interesting observation, however, is that when the integration time is reduced to just $50 \mathrm{~h}$ or even $25 \mathrm{~h}$, the key FTLE ridges tend to become less sharp but do not disappear (see Fig. S2, which makes reference to the example shown in Fig. 3b). This finding is consistent with the fact that, according to Figs. $2 \mathrm{a}$ and $3 \mathrm{~b}$, neighbouring backward trajectories show high drift velocities towards the end of the integration period but also concurrently show a clear separation right from the start. This indicates a certain memory effect after the storm has ceased.

In this study, FTLE fields were analysed on a $1 \mathrm{~km}$ grid, nearly matching the resolution of the marine current fields. Computationally more demanding FTLE analyses on a finer grid would have enabled the identification of structures even smaller than the resolution of the underlying Eulerian hydrodynamic model. Such structures arise, however, from tracer simulations over longer distances (Huhn et al., 2012), thereby filtering more short-term features (Serra and Haller, 2016). 

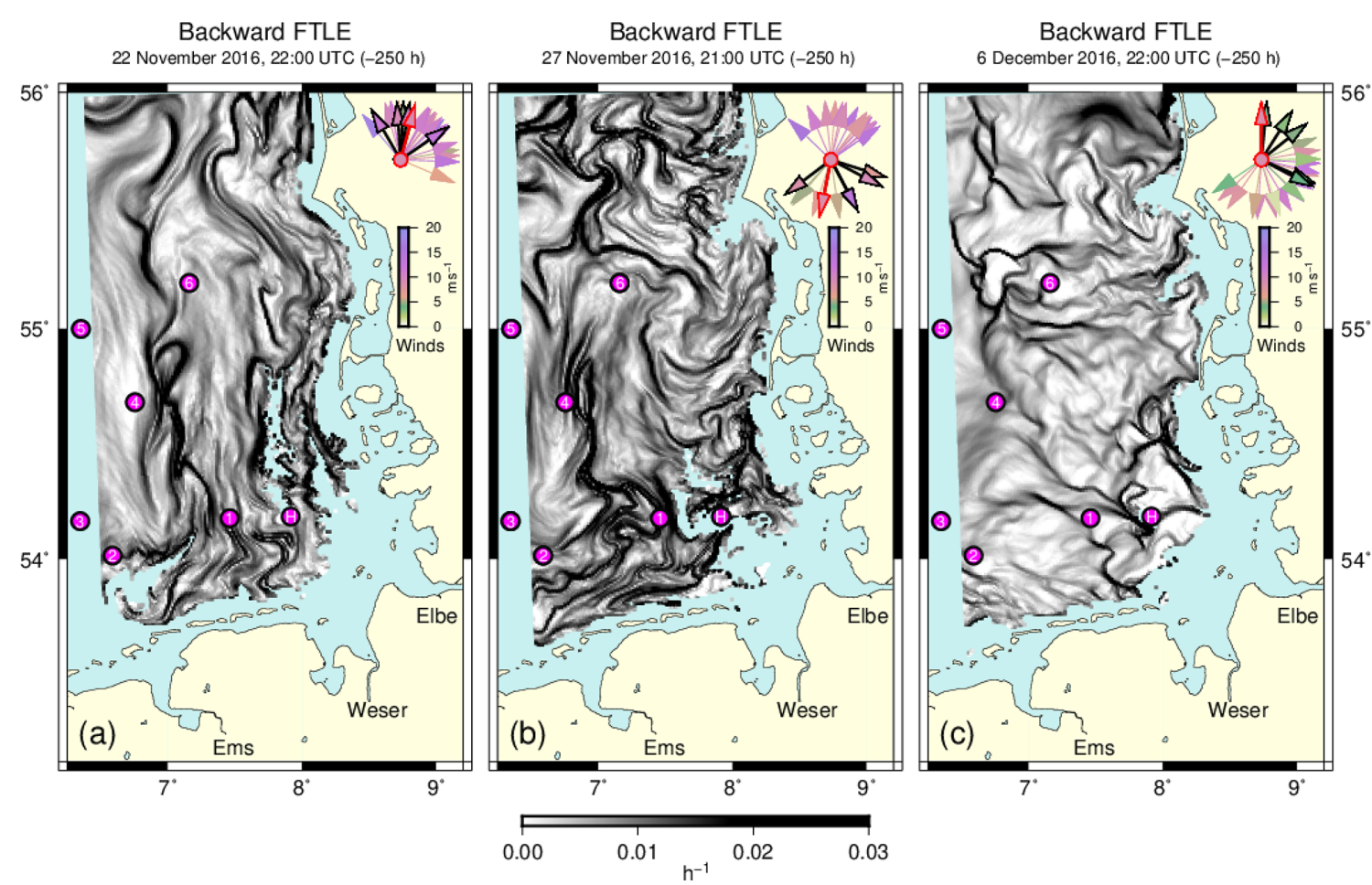

Figure 5. Three backward FTLE fields scheduled with approximately $5 \mathrm{~d}$ and $9 \mathrm{~d}$ in between, extracted from a video available in the Supplement. Magenta circles indicate the locations of the MARNET stations (1-6) and of the island of Heligoland (H). Vectors in the top-right corners show past wind directions (modelled for the location of station 4) at 10-hourly intervals. Different wind speeds are represented by a colour map. Wind vectors at the times of the plots are outlined in red and those during the last $50 \mathrm{~h}$ are outlined in black.

As a result, a clear classification of kinematic LCSs in terms of mesoscale or sub-mesoscale processes seems difficult.

In their study of Lagrangian transports in the Gulf of Mexico, Duran et al. (2018) found patterns of 2D transports that arose from a mere confluence, i.e. normal attraction and tangential stretching without convergence. Lehahn et al. (2007) found satellite observations of chlorophyll filaments in the north-east Atlantic to agree well with simulated geostrophic transports, contracting at and stretching along material lines. Referring to Lapeyre and Klein (2006), they argue that an ageostrophic secondary circulation injecting nutrients from deeper layers may trigger further chlorophyll production. Similarly, Olascoaga et al. (2013, their Fig. 1) show a chlorophyll $a$ plume in the Gulf of Mexico to coincide with a divergence-free attracting LCS. However, at the smaller submesoscale, Hernández-Carrasco et al. (2018) found negative extremes of Lagrangian divergence to coincide with attracting LCSs identified as ridges in the backward FSLE field analysed from HF radar data. Also in the present study, the field of path-averaged divergence FDLD suggested the role of backward FTLE ridges as lines of convergence in coastal waters. This was explicitly shown for the example in Fig. 2 but also pertains to all other examples.

Referring to the example addressed in Fig. 3b, Fig. 6a shows the corresponding field of the Jacobian determinant.
A shorter integration period of only $-100 \mathrm{~h}$ (rather than $-250 \mathrm{~h}$ ) was chosen to exclude the period of strong easterly winds that occurred about $8 \mathrm{~d}$ before the date of the analysis (compare the wind roses in Figs. $3 \mathrm{~b}$ and 6a respectively). Despite the shortened integration time, ridges in the backward Jacobian determinant field (Fig. 6a) coincide well with FTLE ridges (Fig. 3b). Values of the Jacobian determinant substantially deviate from the neutral value of one that corresponds to zero divergence (Fig. 6b). Values further spread with increasing integration time. To exemplify corresponding patterns of transport, Fig. $6 \mathrm{c}$ shows the development of two patches with an either increasing or decreasing area. At each time level, quadrangles are defined by the positions of the four trajectories that emerge from the locations used to calculate the discretized deformation radius (Eq. 2) in their centre. In the more southern example, trajectories originate from locations on a ridge in the Jacobian determinant field. After $100 \mathrm{~h}$ back in time, the initial area of the square has grown by a factor of 3.73 , the value of the determinant shown in the map. By contrast, for the more northern example, the area decreases by a factor of 0.31 . In both examples, the drift behaviour is far from non-divergent.

In both cases, however, substantial stretching also occurs. Final stretches $\mu_{1} / \mu_{2}$ of the example squares in Fig. $6 \mathrm{c}$ amount to 5.52 (red) and 2.36 (green). To differentiate the 
Table 1. Correlations between FTLE and its additive components $\Delta$ and $\Sigma$ (see Eq. 8).

\begin{tabular}{llrrr}
\hline & & $\begin{array}{r}\text { 12 Jun 2015 } \\
\text { (Fig. 2) }\end{array}$ & $\begin{array}{r}\text { 26 Mar 2018 } \\
\text { (Fig. 3b) }\end{array}$ & $\begin{array}{r}\text { 29 Feb 2016 } \\
\text { (Fig. 4) }\end{array}$ \\
\hline corr (FTLE, $\Delta)$ & $-50 \mathrm{~h}$ & 0.41 & 0.59 & 0.68 \\
& $-100 \mathrm{~h}$ & 0.51 & 0.66 & 0.73 \\
& $-250 \mathrm{~h}$ & 0.65 & 0.72 & 0.77 \\
\hline corr (FTLE, $\Sigma)$ & $-50 \mathrm{~h}$ & 0.69 & 0.63 & 0.57 \\
& $-100 \mathrm{~h}$ & 0.65 & 0.57 & 0.47 \\
& $-250 \mathrm{~h}$ & 0.52 & 0.50 & 0.37 \\
\hline
\end{tabular}

For three examples presented in this paper, the table shows the correlations obtained for backward integration times of $\tau=-50,-100$ and $-250 \mathrm{~h}$ respectively.

effects of divergent flows from divergence-free repulsion, Huntley et al. (2015) introduced the decomposition of the FTLE measure into dilation rate $\Delta$ and stretch rate $\Sigma$ (see Eq. 8). For the three examples presented in Figs. 2, 3b and 4 respectively, Table 1 provides the correlations between FTLE and either dilation rate $\Delta$ or stretch rate $\Sigma$. In each case, correlations are given for the three different integration times of $-50,-100$ and $-250 \mathrm{~h}$. Correlations between FTLE and $\Delta$ or $\Sigma$ are both positive and of similar size, indicating that repulsion in the vicinity of backward FTLE ridges indeed occurs as a combination of divergence and stretching. In all three examples, it is interesting to note that the correlations between FTLE and dilation rate $\Delta$ increase with integration time, whereas correlations with stretch rate $\Sigma$ decrease. As a result, the correlation of FTLE with dilation rate $\Delta$ is dominant for the $-250 \mathrm{~h}$ integration time chosen in this study.

The temperature field in Fig. 2c reflects some effects of confluent and possibly also convergent currents. Surface temperature observations by remote sensing might possibly provide a means to confirm simulated FDLD fields. Schrum (1997) showed how the spatial extent of thermohaline stratified areas, a precondition for the occurrence of tidal mixing fronts, depends on wind forcing that possibly induces differential advection. In a recent paper, Chegini et al. (2020) provided a more detailed analysis of different processes that affect stratification and destratification in the German Bight area, including the freshwater buoyancy input. The location of the Elbe River plume again depends on the wind-driven residual circulation, which further substantiates the assumption of atmospheric forcing being the key driver for the generation, movement and extinction of German Bight LCSs.

Relatively persistent FTLE ridges related to the island of Heligoland, for instance, could possibly be relevant for sedimentation processes. However, movements of inertial tracers can substantially differ from those of fluid parcels, so that an analysis of ideal passive tracer trajectories is likely to be too simplistic in that context. The idea of LCSs has been generalized, however, to explicitly include the dynamics of inertial particles (Sapsis and Haller, 2009; Sudharsan et al., 2016; Günther and Theisel, 2017). This theoretical concept has successfully been applied on the scale of ocean eddies (Beron-Vera et al., 2015) but also on the very small scale of jellyfish feeding (Peng and Dabiri, 2009; Sapsis et al., 2011).

Although numerical models can make observers aware of FTLE barriers that move, disappear or newly arise under changing environmental conditions, they can never provide a perfect surrogate nature. Guo et al. (2016) proposed concepts to extend the conventional analysis of deterministic FTLE fields and ridges to uncertain flow conditions. In a comparative study, Hufnagl et al. (2017) found considerable discrepancies between the results from a large number of different North Sea tracer simulations essentially based on vertical mean currents. Wiggins (2005) makes reservations that, in contrast to many engineering applications, the presence and interaction of very different scales in geophysical flows can restrict the possibility of simulating detailed particle drift paths. All things considered, simulated FTLE field will always be imperfect. However, even in the case of inaccurate simulations, simulated FTLE fields will warn users about the key sensitivities of specific model output. If an observation is taken close to a simulated FTLE ridge, a simulated backward trajectory for this location must be used with due care.

This study did not address repelling LCSs in prediction (forward) mode. Drift simulations are important tools employed for tasks such as search and rescue (Breivik et al., 2013). Serra et al. (2020) proposed the use of objective Eulerian coherent structures (OECS) in this context, a concept developed by Serra and Haller (2016) to be used when quick operational decisions are to be made. According to Serra and Haller (2016), OECSs can be understood as short-time limits of LCSs, applicable for a time horizon of a few hours. More long-term forward simulations are feasible and can be afforded in contexts such as ecosystem hindcasts, analysing larval transport and dispersal.

For surface drift simulations, additional uncertainties may arise from the necessity to specify the extent to which nearsurface currents are exposed to a direct wind drag. Callies et al. $(2017 \mathrm{~b}, 2019)$ found that a successful simulation of observed drifter trajectories needed BSHcmod surface currents 


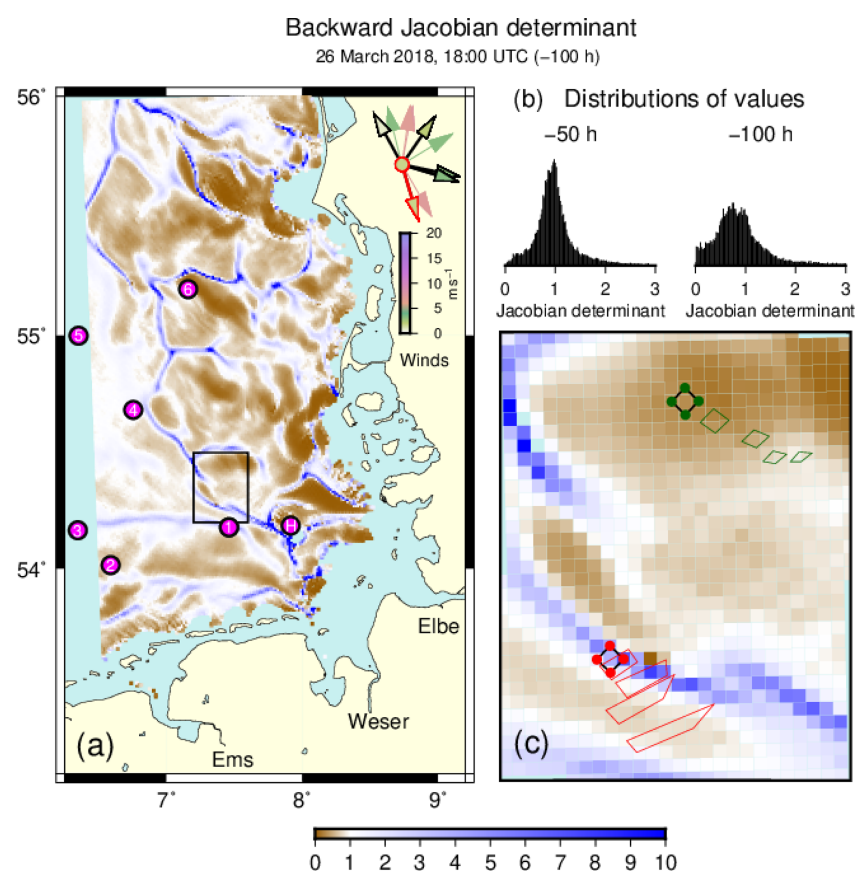

Figure 6. (a) Values of the Jacobian determinant (Eq. 3) for $100 \mathrm{~h}$ backward simulations, initialized on 26 March 2018 (as in Fig. 3b). The few outliers exceeding the maximum value of the colour map were not specifically marked. Any negative values that occurred due to finite initial distances were omitted in the plot. Wind directions during the integration time are shown at 10-hourly intervals in the top-right corner of the panel. The actual wind vector is outlined in red, and those during the last $50 \mathrm{~h}$ are outlined in black. (b) Histograms of Jacobian determinant values on the map for integration times of -50 (left) and $-100 \mathrm{~h}$ (right) respectively. Note that the distributions' flat tales extend beyond the ranges of values shown. (c) Zooming in on the subregion indicated by the black frame in panel (a), this panel shows the time evolution of two square patches, the corners of which are made up by the initial locations (red and green dots) of the four trajectories needed to calculate the discretized deformation gradients (Eq. 2) at the squares' centres. The developments of deformed quadrangles during the $-100 \mathrm{~h}$ integration period are shown at 25-hourly intervals. Factors of area increases or decreases, $\mu_{1} \mu_{2}$ (Eq. 3), are 1.56, 2.50, 3.40 and 3.73 (red) and 0.96, 0.70, 0.42 and 0.31 (green), where the last values equal the values shown in the map. The corresponding stretches, $\mu_{1} / \mu_{2}$, are $1.88,3.01,3.78$ and 5.52 (red) and 1.17, 1.52, 1.98 and 2.36. (green).

to be augmented by a leeway of $0.6 \%$ of $10 \mathrm{~m}$ winds. Besides a small direct wind drag exerted on the drifters themselves, this leeway compensates for insufficient vertical resolution in the archived BSHcmod surface current fields (representing a layer of $5 \mathrm{~m}$ depth). In addition, the leeway may also parameterize wave-related Stokes drift not being considered explicitly (Callies et al., 2017b; Sutherland et al., 2020; Staneva et al., 2021). Example forward FTLE fields including a $0.6 \%$ leeway are shown in Fig. S3. The examples show that FTLE ridges are modified but do not disappear when the smooth fields of a wind-induced leeway are superimposed onto marine currents. This conclusion directly translates to all the backward FTLE fields analysed in this paper.

\section{Conclusions}

The analysis of backward surface tracer simulations in the German Bight region revealed the intermittent presence of linear structures (LCSs) across which the past history of water bodies substantially changes. Such sensitive dependences of backward trajectories on tracer seeding positions, represented by narrow ridges in the FTLE field, could entail differences between in situ observations even at neighbouring locations. Therefore, an evaluation of spatially distributed in situ observations could benefit from the awareness of changing FTLE fields, analysed based on either numerical simulations or possibly HF radar observational data.

In the presence of narrow FTLE ridges, marked differences between observed and simulated tracer trajectories do not necessarily reflect poor model performance. If the location of a simulated LCS does not fully agree with reality, a tracer release point may come to lie on different sides of the separatrices in the model and in nature respectively. In this case, a naive comparison of trajectories could much exaggerate inconsistencies. The same arguments pertain to a comparison of different drift models. Therefore, conventional model evaluations based on individual drift paths might be complemented with a comparison of simulated FTLE fields.

The examples illustrated the variability of German Bight surface layer LCSs under changing wind conditions. For a more comprehensive picture, it could be useful to establish a method that allows for the estimation of the basic characteristics of backward FTLE fields from the recent history of atmospheric forcing. The examples studied suggest that model uncertainties occur particularly in the aftermath of storm conditions. Due to the presence of sometimes complex filamentary structures, a decomposition of FTLE fields in terms of a mean plus a number of weighted anomaly fields does not seem very promising. A more qualitative classification of FTLE fields into a set of categories could be feasible. This issue is left to future research.

Code and data availability. The hydrodynamic data analysed in this paper were obtained from the repository of the German Federal Maritime and Hydrographic Agency (BSH). For access to the archived results of the operational hydrodynamical model BSHcmod, please contact BSH (https://www.bsh.de, last access: 29 March 2021). The Lagrangian drift code PELETS is available upon request from the author.

Supplement. A video is provided (FTLE_2016.avi) that demonstrates the temporal development of the FTLE fields over the course of the year 2016 based on FTLE fields calculated ev- 
ery $7 \mathrm{~h}$. Also some additional figures are included in the supplement. The supplement related to this article is available online at: https://doi.org/10.5194/os-17-527-2021-supplement.

Competing interests. The author declares that there is no conflict of interest.

Acknowledgements. Drift simulations were based on BSHcmod currents provided by the Federal Maritime and Hydrographic Agency (BSH). Graphs were produced using the Generic Mapping Tools (GMT) software available from https://www.soest.hawaii. edu/gmt/, last access: 29 March 2021. I would like to thank Rodrigo Duran for some helpful suggestions. Furthermore, I am grateful for the constructive comments from Jens Meyerjürgens and two anonymous referees.

Financial support. The article processing charges for this openaccess publication were covered by a Research Centre of the Helmholtz Association.

Review statement. This paper was edited by Erik van Sebille and reviewed by two anonymous referees.

\section{References}

Aurell, E., Boffetta, G., Crisanti, A., Palatin, G., and Vulpiani, A.: Growth of noninfinitesimal perturbations in turbulence, Phys. Rev. Lett., 77, 1262-1265, https://doi.org/10.1103/PhysRevLett.77.1262, 1996.

Aurell, E., Boffetta, G., Crisanti, A., Palatin, G., and Vulpiani, A.: Predictability in the large: an extension of the concept of Lyapunov exponent, J. Phys. A, 30, 1-26, https://doi.org/10.1088/0305-4470/30/1/003, 1997.

Baschek, B., Schroeder, F., Brix, H., Riethmüller, R., Badewien, T. H., Breitbach, G., Brügge, B., Colijn, F., Doerffer, R., Eschenbach, C., Friedrich, J., Fischer, P., Garthe, S., Horstmann, J., Krasemann, H., Metfies, K., Merckelbach, L., Ohle, N., Petersen, W., Pröfrock, D., Röttgers, R., Schlüter, M., Schulz, J., Schulz-Stellenfleth, J., Stanev, E., Staneva, J., Winter, C., Wirtz, K., Wollschläger, J., Zielinski, O., and Ziemer, F.: The Coastal Observing System for Northern and Arctic Seas (COSYNA), Ocean Sci., 13, 379-410, https://doi.org/10.5194/os-13-3792017, 2017.

Becker, G. A., Dick, S., and Dippner, J. W.: Hydrography of the German Bight, Mar. Ecol. Prog. Ser., 91, 9-18, 1992.

Beron-Vera, F. J., Olascoaga, M. J., Haller, G., Farazmand, M., Triñanes, J., and Wang, Y.: Dissipative inertial transport patterns near coherent Lagrangian eddies in the ocean, Chaos, 25, 087412, https://doi.org/10.1063/1.4928693, 2015.

Breivik, Ø., Allen, A. A., Maisondieu, C., and Olagon, M.: Advances in search and rescue at sea, Ocean Dynam., 63, 83-88, https://doi.org/10.1007/s10236-012-0581-1, 2013.
Budéus, G.: Frontal variability in the German Bight, Sci. Mar., 53 , 175-185, 1989.

Callies, U., Plüß, A., Kappenberg, J., and Kapitza, H.: Particle tracking in the vicinity of Helgoland, North Sea: A model comparison, Ocean Dynam., 61, 2121-2139, https://doi.org/10.1007/s10236-011-0474-8, 2011.

Callies, U., Gaslikova, L., Kapitza, H., and Scharfe, M.: German Bight residual current variability on a daily basis: principal components of multi-decadal barotropic simulations, Geo.-Mar. Lett., 37, 151-162, https://doi.org/10.1007/s00367-016-0466-2, 2017a.

Callies, U., Groll, N., Horstmann, J., Kapitza, H., Klein, H., Maßmann, S., and Schwichtenberg, F.: Surface drifters in the German Bight: model validation considering windage and Stokes drift, Ocean Sci., 13, 799-827, https://doi.org/10.5194/os-13799-2017, 2017b.

Callies, U., Carrasco, R., Floeter, J., Horstmann, J., and Quante, M.: Submesoscale dispersion of surface drifters in a coastal sea near offshore wind farms, Ocean Sci., 15, 865-889, https://doi.org/10.5194/os-15-865-2019, 2019.

Chegini, F., Holtermann, P., Kerimoglu, O., Becker, M., Kreus, M., Klingbeil, K., Gräwe, U., Winter, C., and Burchard, H.: Processes of stratification and destratification during an extreme river discharge event in the German Bight ROFI, J. Geophys. Res.-Ocean., 125, e2019JC015987, https://doi.org/10.1029/2019JC015987, 2020.

Chen, K., Ni, M., Cai, M., Huang, J. W. D., Chen, H., Wang, X., and Liu, M.: Optimization of a coastal environmental monitoring network based on the Kriging method: A case study of Quanzhou Bay, China, Biomed. Res. Int., 2016, 7137310, https://doi.org/10.1155/2016/7137310, 2016.

Dick, S., Kleine, E., Müller-Navarra, S., Klein, H., and Komo, H.: The operational circulation model of BSH (BSHcmod), Model description and validation, Tech. Rep. 29/2001, BSH, 2001.

Dick, S., Kleine, E., and Janssen, F.: A new operational circulation model for the North Sea and Baltic Sea using a novel vertical cooordinate setup and first results, in: Coastal to Global Operational Oceanography: Achievements and Challenges, Proceedings of the Fifth International Conference on EuroGOOS, 28. Bundesamt für Seeschifffahrt und Hydrographie (BSH)/EuroGOOS Office, 20-22 May 2008, Exeter, UK, edited by: Dalhin, H., Bell, M. J., Flemming, N. C., and Petersen, S. E., Sweden, ISBN 97891-974828-6-8.xii, 557 pp., 2008.

d'Ovidio, F., De Monte, S., Alvain, S., Dandonneau, Y. and Lévy, M.: Fluid dynamical niches of phytoplankton types, P. Natl. Acad. Sci. USA, 107, 18366-18370, https://doi.org/10.1073/pnas.1004620107, 2010.

d'Ovidio, F., Penna, A. D., Trull, T. W., Nencioli, F., Pujol, M.-I., Rio, M.-H., Park, Y.-H., Cotté, C., Zhou, M., and Blain, S.: The biogeochemical structuring role of horizontal stirring: Lagrangian perspectives on iron delivery downstream of the Kerguelen Plateau, Biogeosciences, 12, 55675581, https://doi.org/10.5194/bg-12-5567-2015, 2015

Duran, R., Beron-Vera, F. J., and Olascoaga, M. J.: Extracting quasisteady Lagrangian transport patterns from the ocean circulation: An application to the Gulf of Mexico, Sci. Rep., 8, 5218 , https://doi.org/10.1038/s41598-018-23121-y, 2018. 
Farazmand, M. and Haller, G.: Computing Lagrangian coherent structures from their variational theory, Chaos, 22, 013128, https://doi.org/10.1063/1.3690153, 2012.

Günther, T. and Theisel, H.: Backward finite-time Lyapunov exponents in inertial flows, IEEE Trans. Vis. Comput. Graph., 23, 970-979, https://doi.org/10.1109/TVCG.2016.2599016, 2017.

Guo, H., He, W., Peterka, T., Shen, H.-W., Collis, S. M., and Helmus, J. J.: Finite-time Lyapunov exponents and Lagrangian coherent structures in uncertain unsteady flows, IEEE Trans. Vis. Comput. Graph., 22, 1672-1682, https://doi.org/10.1109/TVCG.2016.2534560, 2016.

Hadjighasem, A., Farazmand, M., Blazevski, D., Froyland, G., and Haller, G.: A critical comparison of Lagrangian methods for coherent structure detection, Chaos, 27, 053104, https://doi.org/10.1063/1.4982720, 2017.

Haller, G.: Distinguished material surfaces and coherent structures in three-dimensional fluid flows, Physica D, 149, 248-277, https://doi.org/10.1016/S0167-2789(00)00199-8, 2001.

Haller, G.: A variational theory of hyperbolic Lagrangian coherent structures, Physica D, 240, 574-598, https://doi.org/10.1016/j.physd.2010.11.010, 2011.

Haller, G.: Lagrangian coherent structures, Annu. Rev. Fluid Mech., 47, 137-162, https://doi.org/10.1146/annurev-fluid010313-141322, 2015.

Haller, G. and Yuan, G.: Lagrangian coherent structures and mixing in two-dimensional turbulence, Physica D, 147, 352-370, https://doi.org/10.1016/S0167-2789(00)00142-1, 2000.

Harrison, C. S. and Glatzmaier, G. A.: Lagrangian coherent structures in the California Current System - sensitities and limitations, Geophys. Astro. Fluid Dynam., 106, 22-44, https://doi.org/10.1080/03091929.2010.532793, 2010.

Hernández-Carrasco, I., Orfila, A., Rossi, V., and Garçon, V.: Effect of small scale transport processes on phytoplankton distribution in coastal seas, Sci. Rep., 8, 8613, https://doi.org/10.1038/s41598-018-26857-9, 2018.

Holt, J. and Umlauf, L.: Modelling the tidal mixing fronts and seasonal stratification of the Northwest European Continental shelf, Cont. Shelf Res., 28, 887-903, https://doi.org/10.1016/j.csr.2008.01.012, 2008.

Hufnagl, M., Payne, M., Lacroix, G., Bolle, L. J., Daewel, U., Dickey-Collas, M., Gerkema, T., Huret, M., Janssen, F., Kreus, M., Pätsch, J., Pohlmann, T., Ruardij, P., Schrum, C., Skogen, M. D., Tiessen, M. C., Petitgas, P., van Beek, J. K., van der Veer, H. W., and Callies, U.: Variation that can be expected when using particle tracking models in connectivity studies, J. Sea Res., 127, 133-149, https://doi.org/10.1016/j.seares.2017.04.009, 2017.

Huhn, F., von Kameke, A., Allen-Perkins, S., Montero, P., Venancio, A., and Pérez-Muñuzuri, V.: Horizontal Lagrangian transport in a tidal-driven estuary - Transport barriers attached to prominent coastal boundaries, Cont. Shelf Res., 39/40, 1-13, https://doi.org/10.1016/j.csr.2012.03.005, 2012.

Huntley, H. S., Lipphardt, B. L., Jacobs, G., and Kirwan Jr., A. D.: Clusters, deformation, and dilation: Diagnostics for material accumulation regions, J. Geophys. Res., 120, 6622-6636, https://doi.org/10.1002/2015JC011036, 2015.

James, I. D.: A three-dimensional numerical shelf-sea front model with variable eddy viscosity and diffusivity, Cont. Shelf Res., 3, 69-98, 1984.
Karrasch, D. and Haller, G.: Do finite-size Lyapunov exponents detect coherent structures?, Chaos, 23, 043126, https://doi.org/10.1063/1.4837075, 2013.

Kim, N.-H. and Hwang, J. H.: Optimal design of water quality monitoring networks in semi-enclosed estuaries, Sensors, 20, 1498, https://doi.org/10.3390/s20051498, 2020.

Krause, G., Budeus, G., Gerdes, D., Schaumann, K., and Hesse, K.: Frontal systems in the German Bight and their physical and biological effects, in: Marine Interfaces Ecohydrodynamics, edited by: Nihoul, J. C. J., Elsevier, Amsterdam, 119-140, 1986.

LaCasce, J. H.: Statistics from Lagrangian observations, Prog. Oceanogr., 77, 1-29, https://doi.org/10.1016/j.pocean.2008.02.002, 2008.

LaCasce, J. H. and Ohlmann, C.: Relative dispersion at the surface of the Gulf of Mexico, J. Mar. Res., 61, 285-312, https://doi.org/10.1357/002224003322201205, 2003.

Lapeyre, G. and Klein, P.: Impact of the small-scale elongated filaments on the oceanic vertical pump, J. Mar. Res., 64, 835-851, https://doi.org/10.1357/002224006779698369, 2006.

Lehahn, Y., d'Ovidio, F., Lévy, M., and Heifetz, E.: Stirring of the northeast Atlantic spring bloom: A Lagrangian analysis based on multisatellite data, J. Geophys. Res., 112, C08005, https://doi.org/10.1029/2006JC003927, 2007.

Lucas, J., Koester, I., Wichels, A., Niggemann, J., Dittmar, T., Callies, U., Wiltshire, K. H., and Gerdts, G.: Short-term dynamics of North Sea bacterioplankton-dissolved organic matter coherence on molecular level, Front. Microbiol., 7, 321, https://doi.org/10.3389/fmicb.2016.00321, 2016.

Meyerjürgens, J., Ricker, M., Schakau, V., Badewien, T. H., and Stanev, E. V.: Relative dispersion of surface drifters in the North Sea: The effect of tides on mesoscale diffusivity, J. Geophys. Res.-Ocean., 124, e2019JC015925, https://doi.org/10.1029/2019JC015925, 2020.

Molcard, A., Andrew C, P., and Özgökmen, T. M.: Directed drifter launch strategies for Lagrangian data assimilation using hyperbolic trajectories, Ocean Model., 12, 268-289, https://doi.org/10.1016/j.ocemod.2005.06.004, 2006.

Olascoaga, M. J., Beron-Vera, F. J., Haller, G., Triñanes, J., Iskandarani, M., Coelho, E. F., Haus, B. K., Huntley, H. S., Jacobs, G., Kirwan Jr., A. D., Lipphardt Jr., B. L., Özgökmen, T. M., Reniers, A. J. H., and Valle-Levinson, A.: Drifter motion in the Gulf of Mexico constrained by altimetric Lagrangian coherent structures, Geophys. Res. Lett., 40, 61716175, https://doi.org/10.1002/2013GL058624, 2013.

Orre, S., Gjevik, B., and LaCasce, J. H.: Characterizing chaotic dispersion in a coastal tidal model, Cont. Shelf Res., 26, 1360-1374, https://doi.org/10.1016/j.csr.2005.11.015, 2006.

Peacock, T. and Haller, G.: Lagrangian coherent structures: the hidden skeleton of fluid flows, Phys. Today, 66, 41-47, https://doi.org/10.1063/PT.3.1886, 2013.

Peng, J. and Dabiri, J. O.: Transport of inertial particles by Lagrangian coherent structures: application to predator-prey interaction in jellyfish feeding, J. Fluid Mech., 623, 75-84, https://doi.org/10.1017/S0022112008005089, 2009.

Pierrehumbert, R. T. and Yang, H.: Global chaotic mixing on isentropic surfaces, J. Atmos. Sci., 50, 2462-2480, https://doi.org/10.1175/15200469(1993)050<2462:GCMOIS>2.0.CO;2, 1993. 
Poje, A. C., Toner, M., Kirwan Jr., A. D., and Jones, C. K. R. T.: Drifter launch strategies based on Lagrangian templates, J. Phys. Oceanogr., 32, 1855-1869, https://doi.org/10.1175/15200485(2002)032<1855:DLSBOL >2.0.CO;2, 2002.

Press, W. H., Teukolsky, S. A., Vetterling, W. T., and Flannery, B. P.: Numerical Recipies in FORTRAN - The Art of Scientific Computing, Cambridge University Press, Cambridge, UK, 2 Edn., 963 pp., 1992.

Ricker, M. and Stanev, E. V.: Circulation of the European northwest shelf: a Lagrangian perspective, Ocean Sci., 16, 637-655, https://doi.org/10.5194/os-16-637-2020, 2020.

Sansón, L. Z., Pérez-Brunius, P., and Sheinbaum, J.: Surface relative dispersion in the southwestern Gulf of Mexico, J. Phys. Oceanogr., 47, 387-403, https://doi.org/10.1175/JPO-D16-0105.1, 2017.

Sapsis, T. and Haller, G.: Inertial particle dynamics in a hurricane, J. Atmos. Sci., 66, 2481-2492, https://doi.org/10.1175/2009JAS2865.1, 2009.

Sapsis, T., Peng, J., and Haller, G.: Instabilities on prey dynamics in jellyfish feeding, Bull. Math. Biol., 73, 1841-1856, https://doi.org/10.1007/s11538-010-9594-4, 2011.

Scales, K. L., Hazen, E. L., Jacox, M. G., Castruccio, F., Maxwell, S. M., Lewison, R. L., and Bograd, S. J.: Fisheries bycatch risk to marine megafauna is intensified in Lagrangian coherent structures, P. Natl. Acad. Sci. USA, 115, 7362-7367, https://doi.org/10.1073/pnas.1801270115, 2018.

Schrum, C.: Thermohaline stratification and instabilities at tidal mixing fronts: results of an eddy resolving model for the German Bight, Cont. Shelf Res., 17, 689-716, https://doi.org/10.1016/S0278-4343(96)00051-9, 1997.

Schulz, J.-P. and Schättler, U.: Kurze Beschreibung des Lokal-Modells Europa COSMO-EU (LME) und seiner Datenbanken auf dem Datenserver des DWD, available at: https://www.dwd.de/SharedDocs/downloads/, 2014.

Serra, M. and Haller, G.: Objective Eulerian coherent structures, Chaos, 26, 053110, https://doi.org/10.1063/1.4951720, 2016.

Serra, M., Sathe, P., Rypina, I., Kirincich, A., Ross, S. D., Lermusiaux, P., Allen, A., Peacock, T., and Haller, G.: Search and rescue at sea aided by hidden flow structures, Nat. Commun., 11, 2525, https://doi.org/10.1038/s41467-020-16281-x, 2020.

Shadden, S. C., Lekien, F., and Marsden, J. E.: Definition and properties of Lagrangian coherent structures from finite-time Lyapunov exponents in two-dimensional aperiodic flows, Physica D, 212, 271-304, https://doi.org/10.1016/j.physd.2005.10.007, 2005

Shadden, S. C., Lekien, F., Paduan, J. D., Chavez, F. P., and Marsden, J. E.: The correlation between surface drifters and coherent structures based on high-frequency radar data in Monterey Bay, Deep-Sea Res. Pt. II, 56, 161-172, https://doi.org/10.1016/j.dsr2.2008.08.008, 2009.

Smagorinsky, J.: General circulation experiments with the primitive equations, I. the basic experiment, Mon. Weather Rev., 91, 99-164, https://doi.org/10.1175/15200493(1963)091<0099:GCEWTP>2.3.CO;2, 1963.

Smith, S. and Banke, E.: Variation of the sea surface drag coefficient with wind speed, Q. J. Roy. Meteor. Soc., 101, 665-673, https://doi.org/10.1002/qj.49710142920, 1975.
Stanev, E. V., Schulz-Stellenfleth, J., Staneva, J., Grayek, S., Grashorn, S., Behrens, A., Koch, W., and Pein, J.: Ocean forecasting for the German Bight: from regional to coastal scales, Ocean Sci., 12, 1105-1136, https://doi.org/10.5194/os-12-11052016, 2016.

Stanev, E. V., Badewien, T. H., Freund, H., Grayek, S., Hahner, F., Meyerjürgens, J., Ricker, M., Schöneich-Argent, R. I., Wolff, J.-O., and Zielinski, O.: Extreme westward surface drift in the North Sea: Public reports of stranded drifters and Lagrangian tracking, Cont. Shelf Res., 177, 24-32, https://doi.org/10.1016/j.csr.2019.03.003, 2019.

Staneva, J., Ricker, M., Alvarez, R. C., Breivik, Ø., and Schrum, C.: Effects of wave-induced processes in a coupled waveocean model on particle transport simulations, Water, 13, 415, https://doi.org/10.3390/w13040415, 2021.

Sudharsan, M., Brunton, S. L., and Riley, J. J.: Lagrangian coherent structures and inertial particle dynamics, Phys. Rev. E, 93, 033108, https://doi.org/10.1103/PhysRevE.93.033108, 2016.

Sündermann, J. and Pohlmann, T.: A brief analysis of the North Sea physics, Oceanologia, 53, 663-689, https://doi.org/10.5697/oc.53-3.663, 2011.

Sutherland, G., Soontiens, N., Davidson, F., Smith, G. C., Bernier, N., Blanken, H., Schillinger, D., Marcotte, G., Röhrs, J., Dagestad, K.-F., Christensen, K. H., and Breivik, Ø.: Evaluating the leeway coefficient for different ocean drifters using operational models, arXiv e-prints, arXiv:2005.09527, https://ui. adsabs.harvard.edu/abs/2020arXiv200509527S, 2020.

Teeling, H., Fuchs, B. M., Becher, D., Klockow, C., Gardebrecht, A., Bennke, C. M., Kassabgy, M., Huang, S., Mann, A. J., Waldmann, J., Weber, M., Klindworth, A., Otto, A., Lange, J., Bernhardt, J., Reinsch, C., Hecker, M., Peplies, J., Bockelmann, F. D., Callies, U., Gerdts, G., Wichels, A., Wiltshire, K. H., Glöckner, F. O., Schweder, T., and Amann, R.: Substratecontrolled succession of marine bacterioplankton populations induced by a phytoplankton bloom, Science, 336, 608-611, https://doi.org/10.1126/science.1218344, 2012.

Tian, F., He, Q., Liu, Z., and Chen, G.: Extracting Lagrangian coherent structures in the Kuroshio current system, Ocean Dynam., 69 , 641-656, https://doi.org/10.1007/s10236-019-01262-6, 2019.

van Sebille, E., Griffies, S. M., Abernathey, R., Adams, T. P., Berloff, P., Biastoch, A., Blanke, B., Chassignet, E. P., Cheng, Y., Cotter, C. J., Deleersnijder, E., Döös, K., Drake, H. F., Drijfhout, S., Gary, S. F., Heemink, A. W., Kjellsson, J., Koszalka, I. M., Lange, M., Lique, C., MacGilchrist, G. A., Marsh, R., Mayorga Adame, C. G., McAdam, R., Nencioli, F., Paris, C. B., Piggott, M. D., Polton, J. A., Rühs, S., Shah, S. H., Thomas, M. D., Wang, J., Wolfram, P. J., Zanna, L., and Zika, J. D.: Lagrangian ocean analysis: Fundamentals and practices, Ocean Model., 121, 4975, https://doi.org/10.1016/j.ocemod.2017.11.008, 2018.

Wiggins, S.: The dynamical systems approach to Lagrangian transport in oceanic flows, Annu. Rev. Fluid Mech., 37, 295-328, https://doi.org/10.1146/annurev.fluid.37.061903.175815, 2005. 